purpose of modifying its behaviour, by eliciting an inappropriate response or inhibiting an appropriate one.

The term 'pheromone' has been coined to denote chemical signals which emanate from one individual and evoke a behavioural or developmental response in a second individual of the same species ${ }^{1}$. A pheromone might, there. fore, be used as a metarchon, but the latter term also embraces food attractants and multi-component odours, as well as such physical agents as lights or sounds.

I thank Dr. Malcolm F. McGregor for his advice.

British Columbia Research Council,

\section{R. H. WRIGHT}

${ }^{2}$ Karlson, P., and Lüseher, M., Nature, 183, 55 (1959).

\title{
Paralogy, a Concept Complementary to Homology and Analogy
}

IN the application in practice of the concept of homology it is necessary to keep taxonomical considerations constantly in mind if false homologies are not to be drawn ${ }^{1}$.

It would seem that there is also some need to consider the concepts of homology and of analogy and to delimit a third and complementary concept, which might be tormed 'paralogy'.

For meaningful discussion to be possible it is essential that there should be strict uniformity of usage in regard to the important concepts of homology and analogy, but, as was pointed out by Boyden ${ }^{3}$, strict usage has by no means always been the rule. When working some years ago in the Department of Anatomy of the University of Sydney this point was forcibly brought home to me. Indeed, even in books devoted to comparative anatomy, it is possible to find examples of looseness of usage of both the term 'homology' and the term 'analogy', or their related parts of speech.

For the meaning of these concepts we can do no better than to go back to Richard Owen, who first clearly defined them in the glossary to his Lectures on the Comparative Anatomy and Physiology of the Invertebrate Animals, delivered at the Royal College of Surgeons of England, and published in 1843: "Analogue. A part or organ in one animal which has the same function as another part or organ in a different animal" and "Homologue. The same organ in different animals under every variety of form and function."

While these definitions are, perhaps, not perfect as such, the nature of the concepts is clearly indicatod. The confusion in the usage of terms relating to these concepts, and in their practical application, appears to have been in part engendered by the lack of explicit definition of the complementary concept of purely anatomical or structural resemblance, for which the term 'paralogy' is suggested. Following Owen, its meaning may be indicated thus: 'Paralogue'-a part or organ in one animal similar in anatomical or microanatomical structure to a part or organ in a different animal.

Paralogy, then, refers only to anatomical similarity and has no phylogenetic or functional implications. Although lacking the comparative anatomical importance of true morphological correspondence (homology) and the comparative physiological significance of functional resemblance (analogy), a term which may help in limiting the drawing of false homologies on the basis of superficial resemblance in structure appears to be amply justified.

Department of Pathology,

Bankstown District Hospital, Sydney,

Now South Wales.

${ }^{1}$ See Hunter, I. J., Nature, 182, 1818 (1958).

"Thesis, Univ. Sydney, 1946.

${ }^{3}$ Quart. Rev. Biol., 18, 228 (1943).

\section{VIROLOGY}

\section{Transfer of Lily Curl Stripe by a Leaf Union Method Applicable to Monocotyledonous Plants}

CURL-STRIPE disease has seriously affected certain plantings of Lilium longiflorum Thunb. in Oregon and California. Control approaches have been uncertain because occurrence patterns and symptomology were equally indicative of nutritional imbalance or virus ætiology and because we had been unable to transmit the disease ${ }^{1}$. Early-season symptoms, central striping of young leaves due to retardation of plastid formation, followed by curling and twisting of leaves, are striking. Such symptoms may continue or, more usually, later formed foliage may be normal. Bulbs from such plants may or may not produce visibly diseased plants the following year. Such symptom variability is atypical of virus infections of bulb plants.

Initially, the presence of a soil-borne virus, probably tobacco rattle, was suspected. Tests by us and by Dr. R. G. Grogan, of the University of California, proved that while rattle virus is occasionally present in Easter lilies, it is certainly not the cause of curl-stripe. Numerous inoculations over a 5-year period failed to isolate a probable virus from typically diseased plants or to effect a transfer from lily to lily. Probable virus ætiology was indicated, however, by electron microscopy and by the development of an antiserum which gave a positive Ouchterlony agar doublediffusion reaction to sap from typically diseased plants. Virus ætiology has now been verified by infecting 20 of 22 lilies by leaf union inoculation. The procedure should be applicable to similar problems in tropical diseases of coconut and maize.

The objective is to fasten the distal half of an infected leaf to the basal half of a leaf on a test plant in such fashion that the cut ends of the parallel veins will be joined and union will occur. The equipment needed is two razor blades, strips of paper masking tape approximately $20 \mathrm{~mm} \times 40 \mathrm{~mm}$ and a spectacle-type magnifier which can be worn. Two operators are required so the union can be made and sealed in $30 \mathrm{sec}$ or less. A leaf on the test plant is cut in two with a razor blade and a piece of tape attached to the lower surface so it extends out about $10 \mathrm{~mm}$ beyond the cut end of the leaf (Fig. 1). Then the distal half of the leaf cut from the infected plant is fitted to the basal half of the test plant leaf so the ends of the veins meet. Slight magnification is needed to ensure adequate joining of the veins. The sticky tape extending beyond the cut end of the test plant leaf enables one to hold both cut ends in position until an assistant can fit a second piece of tape above them to form a waterproof sandwich.

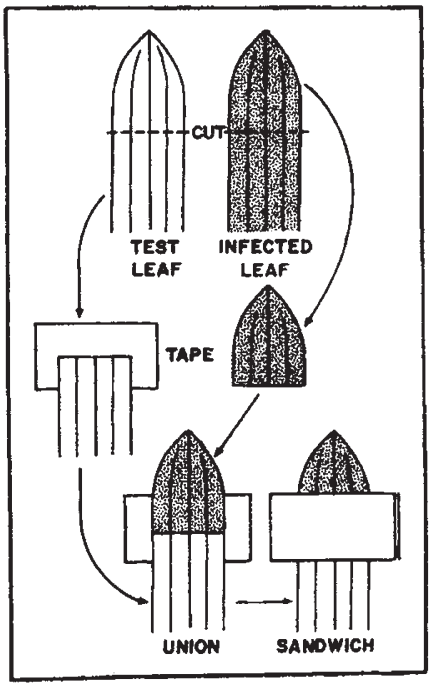

Fig. 1 